\title{
EL APRIORISMO EN LA SEMANTIZACIÓN Y EN EL ANÁLISIS DEL TEXTO LITERARIO
}

Francisco Quintana Docio

Universidad de Valladolid

La experiencia universitaria como estudiante y como docente me ha llevado a pensar hace tiempo que, queriendo o sin quererlo, se promueve a veces una lectura hipersemantizada del texto literario - una supercaptación, hallazgo o asignación de significados-, y se inculcan modelos de interpretación semántico-analítica que acaban rigiendo de un modo apriorístico las orientaciones semánticas correspondientes a los objetos, seres y fenómenos en general -temáticos, constructivos y elocutivos- puestos en juego en el texto objeto de lectura y, sobre todo, objeto de análisis.

Enfrentados a la detección y análisis de los elementos textuales con pertinencia significativa surgen, ciertamente, dos problemas importantes a este respecto: a) el semantizar lo casual o que simplemente está como componente del «efecto de realidad» del texto literario, y b) la asignación general a cualquier texto -en cualquier contexto- de valores significativos y simbolicos, fundamentalmente en correlación dual, conocidos como dominantes antropológicas o frecuentes en otros textos.

a) Atendiendo al primer problema, podemos remontarnos al estructuralismo y su principio general de que todo texto tiene una estructura con un conjunto de elementos interrelacionados, correspondiéndole a cada uno de ellos, indefectiblemente, una función dentro de la totalidad. En el plano semántico y en el texto artístico el paso inmediato fue el considerar que todos los componentes 
tienen una función sígnica (un valor significativo). Hace unos pocos años, dilucidando las características del especial proceso de comunicación literaria, L. Doležel, apoyándose en J. Mukařovský, llamaba la atención sobre el fenómeno de semantización total de la obra literaria:

All the «parts» of the complex sign as well as all the functional relationships among the individual parts and between the parts and the whole, are made bearers of signification: «Each constituent of the work of art is a vehicle of a certain partial meaning; the sum total of these partial meanings, ordered into higher and higher units, is the work as a complex semantic whole» (Mukařovský). [...]. All parts of the poetic structure are vehicles of meaning. (L. Doležel, 1986, pp. 16 y 17).

Decía también J. Mukařovský en su conferencia «Sobre el estructuralismo»: «¿Cuáles son los componentes de la obra de arte capaces de ser portadores de significaciones que colaboren en la creación de su sentido global? [...] todos los componentes sin distinción». Y aclara que son tanto los llamados tradicionalmente componentes «formales» (fónicos, formas gramaticales, componentes sintácticos de construcción) como los que llamamos «temáticos» (1946, pp. 162 y 163). A Doležel le parece que la teoría de Mukařovský de la «total semantization of the poetic structure and his conception of poetic meaning as dynamic semantic accumulation belong to the highest achievements of Prague school semiotic poetics» (1986, pp. 17-18). En este aspecto habría que recordar al menos a I. Tinianov, que había destacado en su caracterización del texto poético, si quizá no tanto la semantización de todos los componentes, sí el refuerzo significativo que adquiere hasta la palabra más trivial en el verso por estar sometida a una dinamización textual rítmica y sintáctico-semántica (cfr. I. Tinianov, 1924, especialmente pp. 77-87) ${ }^{1}$. En esta órbita destaca la aportación posterior de Y. M. Lotman, quien se esfuerza por distinguir las perspectivas del creador y del receptor, señalando que «para el lector que percibe el texto como artístico, no hay nada casual. [...]. Semantiza la fonología, la rima [...]. Esto significa el triunfo del punto de vista del lector, quien percibe todos los detalles del texto como portadores de significadon (1970, pp. 42 y 43). Lotman no se muestra absolutista en este sentido, ya que había afirmado que «la relación entre lo casual y lo sistemático [funcionalmente significativo] en el texto artístico

1 En nuestro país A. García Berrio llamó poderosamente la atención sobre esta teorfa de Tinianov en el capítulo IV de su Significado actual del formalismo ruso, 1973 . 
posee distinto significado para el transmisor y para el receptor. Al recibir un mensaje artístico, [...], el receptor construye un determinado modelo [de descodificación]. Pueden surgir aquí sistemas que organicen los elementos casuales del texto confiriéndoles significación. De este modo, al pasar del emisor al receptor, puede aumentar el número de elementos estructurales significativos» (ibid., pp. 38-39). Simplemente cree que ante un texto literario - básicamente se refiere al poético- hay una "gran tendencia a interpretar todo como significante» (ibid., p. 29) y «se amplía considerablemente para el lector la capacidad semántica del lenguaje» (ibid., p. 43). Para Lotman cada detalle, y el texto artístico en su conjunto, están insertos en sistemas de relaciones que hoy llamaríamos co-textuales (interacciones internas) y pragmático-contextuales (marco referencial, otros textos, intenciones significativas del autor, disposición alertada y «enciclopedia» del receptor...) que semantizan los constituyentes del texto, además dando lugar a una especial concentración y densidad polisignificativa. Es famosa su anotación de que hasta el «ruido» - los brazos partidos de la Venus de Milo, el oscurecimiento de los cuadros a causa del tiempo- se transforma en el arte en información semántica (ibid., pp. 101-102).

Hagamos un poco de erudición haciendo notar la afinidad de las apreciaciones de Lotman con un texto de R. Barthes unos años anterior, texto que de todos modos nos interesaba destacar para nuestro propósito:

En un relato, ¿todo es funcional? ¿Todo, hasta el menor detalle, tiene un sentido? [...] todo, en diverso grado, significa algo en él. [...]. Aun cuando un detalle pareciera irreductiblemente insignificante, rebelde a toda función, no dejará de tener al menos, en última instancia, el sentido mismo del absurdo o de lo inútil: todo tiene sentido o nada lo tiene. Se podría decir, en otras palabras, que el arte no conoce el ruido (en el sentido informativo del término): [...] no hay, nunca hay en su sistema unidades perdidas. (1966, pp. 16-17).

Para Barthes en aquel momento todo en un relato tiene una función significativa, ya como función actancial, ya como indicio - caracterológico, sentimental, de motivaciones, intenciones..., a través de inferencias metonímicaso ya como elemento simbólico. Barthes distingue, según su «importancia» significativa, funciones cardinales y funciones subsidiarias o atenuadas, cuya función es hacer de transición y relleno entre las cardinales, etc. También habla de informaciones que meramente «sirven para autentificar la realidad del referente, para enraizar la ficción en lo real: es un operador realista» (ibid., p. 22. 
Véanse pp. 18-22). Sólo dos años después Barthes retomaba esta última consideración dando una clave interpretativo-analítica que nunca debería dejarse de tener en cuenta, pese a su problemática y variable aplicación: en un relato, en una especie de "lujo» natural de la narración, se encuentran también anotaciones sin ninguna función, «detalles inútiles», in-significantes; unidades irreductibles del análisis funcional que Barthes orienta como portadoras de una «función» nada despreciable: colaboran al "efecto de realidad", mantienen la «ilusión referencial» de un texto ficcional en el que se incluye en parte la presentación de la simple realidad concreta sólo como algo que ontológicamente es y está, que en este caso sólo significa y connota «realidad» (R. Barthes, 1968).

Ciertamente, cuando la pragmática semiótica expone el principio de la semantización de los elementos en la literatura - y especialmente en la poesíacomo característica de lo que suele llamarse «contemplación estética», dada la peculiar condición comunicativa de un texto fuera de situación inmediata, etc., etc., nos sentimos aludidos como receptores que participamos de ese fenómeno de especial disposición perceptiva ante lo que se nos da o tomamos como obra artística (disposición receptora proclive a semantizar elementos in-significantes $e$ inadvertidos en otras condiciones) ${ }^{2}$. Sin embargo, nunca debiera olvidarse de ese reducto dentro del texto artístico, más ontológico que semiósico, que responde al barthiano «efecto de realidad»: como la realidad, también el arte contiene cosas que son o están deliberada o casualmente así, sin designios ni latencias significativas. $\mathbf{R}$. Barthes, al esbozar una teoría semiológica general, llamó función-signo a los objetos de uso del mundo real, con una función utilitaria, signos en todo caso de esa función o uso (1964, pp. 43-44 y 69). Teóricos del teatro como P. Bogatyrev, J. Honzl o J. Veltrusky plantearon ya desde los años 1938 y 1940 que el escenario teatral tiene el carácter de semantizar todo lo que aparece en él. De ahí que muy oportunamente M. C. Bobes Naves haya señalado que el teatro convierte a los función-signos en verdaderos signos, formantes

2 Recordemos ese precioso texto de G. Genette donde, a propósito de la poesía, dice que la verdadera «estructura» del lenguaje poético «n'est pas d'être une forme particulière, définie par ses accidents spécifiques [les artifices], mais plutôt un état, [generado en el lector y su «attitude de lecture»], un degré de présence et d'intensité auquel peut être amené, pour ainsi dire, n'importe quel énoncé, à la seule condition que sétablisse autour de lui cette marge de silence qui l'isole au milieu (mais non a l'écart) du parler quotidien» (1969, p. 150). Una visión afín muestra más tarde, entre otros, R. Posner, planteando las bases específicas ya no de un «lenguaje poeticom, sino del proceso semiótico de la «comunicación poética» o «uso pótico del lenguaje» asumido como tal por el receptor (proceso comunicativo kestéticom en el que se proyectan una serie de agentes y códigos socioculturales sobre el uso y recepción del lenguaje) (cfr. R. Posner, 1976, especialmente pp. 130-131). 
(signos circunstanciales) que adquieren un determinado valor significativo en el contexto y los limites de la obra. No obstante, también aquí hay que reconocer el problema de que «algunos objetos o acciones de la escena que no se emiten con intención semiósica, pueden interpretarse en el conjunto con un significado» (M. C. Bobes Naves, 1989, p. 147) ${ }^{3}$. También para el teatro conviene reivindicar la no pertinencia absoluta de interpretar como signos, índices y símbolos todos los componentes de la escena, considerando la existencia de función-signos y de aspectos presentes por el mero «efecto de realidad» 4 .

Sólo quiero, pues, llamar la atención desde estas páginas sobre la no necesidad ni a veces pertinencia de semantizar -en la lectura-o dar relevancia sémica -en el análisis-a todos los constituyentes de la obra artística ${ }^{5}$.

b) El otro problema que aquí planteo es que la práctica analítica - y la teoría enfocada hacia ese ejercicio- contribuye en muchos casos a establecer apriorismos o pautas preestablecidas en lo relativo a los valores sémicos y simbólicos asignables al texto, que penetran con todo poder en la mente de las personas sometidas - por gusto o por fuerza - a dicha tarea analítica.

Yo recuerdo mi perplejidad, por ejemplo, ante el detectivesco afán - promovido por la estilística en su más amplio sentido- por reconocer que, como la vocal $a$ nos parece más propicia a asociarla a sensaciones de claridad positi$v a$, y las vocales $o$ y $u$ a sensaciones de oscuridad adversa, cualquier recurrencia de la $u$, por poco que se ajustase al contexto - y el contexto abarcaba todo lo doloroso-, daba pie a hablar de oscuridad y negatividad. Eso aunque el verso «una luz sube por el horizonte ruso» sólo les podía parecer oscuro y luctuo-

3 Sobre esta cuestión de la capacidad semantizadora del escenario, véase M. C. Bobes Naves, 1987 , pp. $43,52,79$ y 85-86.

4 En esto se muestra M. C. Bobes Naves muy precavida, concordando con A. Ubersfeld en que «no es necesario interpretar todo y relacionar todo para dar sentido a la obra» $(1987$, p. 94). Y también: «Bogatyrev advirtio que todo lo que está en el escenario actúa como signo, y es una tesis admitida generalmente, con las matizaciones que hemos venido destacando, ya que hay signos, formantes y objetos sin relaciones semióticas* (ibid., p. 95).

5 Dentro de la semantización, y aunque sólo ha quedado aludido, tenemos el interpersonalmente irresoluble problema de asignar contenidos simbólicos y alegóricos a signos y textos a los que tal vez les baste una lectura en el nivel de su «contenido* intelectual, sensorial y emocional inmediato. Sobre los usos y abusos de las hermeneuticas simbolicas, puede recordarse el apasionado alegato de S. Sontag «Contra la interpretación» (1964), en que, frente al afan de las diversas hermenéuticas -entre las modernas, las psicoanalítica y la marxista- por revelar concia de afrontar deros* latentes - producto de un ejercicio intelectual-, defiende la experiencia de afrontar y disfrutar en primer término - si no en exclusivo, y fuese cual fuese la pretensión primero oultima del autor- lo que el texto artístico presenta en su inmediatez sensorial y emocional (pueden verse los ejemplos literarios y cinematográficos con que ilustra su propuesta). 
so a los anticomunistas, y no precisamente por sugestiones del colorido vocálico. Asociar un encabalgamiento abrupto o un hipérbaton a un inarmónico movimiento físico, $o$ anímico en caso de no hallarnos ante una gongorina cabra saltando, acababa siendo tarea cuasiautomática. Una vez familiarizados con el código de relaciones recursos-efectos expresivos, no era difícil hacer encajar contenidos y procedimientos.

La crítica psicoanalítica más reductora, por su parte, aportó sus excesos, famosos desde la obsesión freudiana por ver el mundo bajo el prisma causal y simbólico de la libido sexual y las consecuencias del complejo edípico. Desde el fácil presupuesto de que todo lo protuberante o alargado era fálico y toda concavidad asociable al sexo femenino ${ }^{6}$, podía disculpársele al mundo físico, en su entidad ontológica, su inundación de sexos masculinos y femeninos, pero cualquier imaginación o consideración sígnica de un objeto quedaba sometida a estas leyes, difíciles de discutir porque correspondían a impulsos del subconsciente. La culminación era soñar o presentar en una construcción ficcional una campana - con su badajo - o un zapato - con su cavidad, su punta y el pie que lo calza-, favorecidas síntesis falo-vaginales. No puedo dejar de transcribir la burla de T. Eagleton a propósito de este tipo de superestructuras simbólicas:

Supongamos que estamos analizando un cuento en el cual un chico se va de casa después de un disgusto con su padre, que se pone a caminar por el bosque y a la hora más calurosa del día se cae en un hoyo muy profundo. El padre sale a buscarlo, se asoma por el borde del hoyo pero no puede ver al chico a causa de la oscuridad. En ese momento el sol llega al cenit, ilumina con sus rayos el fondo del hoyo y permite al padre rescatar a su hijo. Después de una feliz reconciliación ambos regresan a casa.

Quizá no se trate de un relato muy emocionante, pero tiene la ventaja de la simplicidad. Por supuesto, puede interpretarse de muchas maneras diferentes. Un crítico psicoanálitico podrfa detectar bien definidos indicios del complejo de Edipo, y explicar que la carda del chico en aquel hoyo es un castigo que inconscientemente desea imponerse por haber roto con su padre, lo cual quizá constituya una forma de castración simbólica o un recurso simb6lico enfocado al vientre materno. (1983, p. 118).

6 Sé que simplifico, pero no me faltan apoyos importantes en lo concemiente a este mismo tipo de crítica de la hermenéutica freudiana más pansexualista y reductiva, como el de $G$. Durand en La imaginación simbólica (1964, pp. 48-54) o el satírico antipoema «Sigmund Freud», de Nicanor Parra (1972, pp. 212-216). 
De modo tal vez afín, el estructuralismo ha favorecido la imposición de la estructura mental dualista para aprehender y apreciar la textura y constitución semántica de la obra artística. El binarismo fonológico de Trubetzkoy, tan fuertemente sancionado por Jakobson, fue llevado a la antropología por LéviStrauss, y a la teoría y crítica literarias por una legión de estudiosos fascinados y animados por lo bien que quedaban explicadas las cosas -en cuadros y gráficos impecables - seccionadas opositivamente en dos vertientes. Era muy gratificante que, a la vista de un aspecto o valor, el análisis no tardara en encontrar -y si tardaba, más aplauso para el esfuerzo o el ingenio- su aspecto opuesto $o$ en franco contraste. No había interior sin exterior, dentro sin fuera, arriba sin abajo, abierto sin cerrado, luminoso sin oscuro, estático sin dinámico..., y sus correspondientes valores antitéticos asociados en vertiente eufórica o disfórica. Bastaba un detalle, y si no un sobreentendido, y los ejes semánticos opositivos daban materia y cauce al análisis.

La antropología de lo imaginario, dada su búsqueda de lo universal arquetípico, es uno de los campos que predisponen más a la extensión generalizadora -ella misma parece generalizar y simplificar demasiado con su categorización de regímenes simbólicos y estrategias imaginarias generales ante el tiempo-, precisamente donde quizá es más arriesgada, ya que la gran característica que uno deduce de los valores simbólicos asignados por el hombre a objetos, seres o movimientos es su polivalencia significativa, manifestándose muchas veces en bivalencia antitética ${ }^{7}$. Se puede elegir en cada caso según convenga, ya que hay caídas en el horror y descensos a la maravilla; la cueva del terror puede ser gruta encantada; hay cuevas-sepulcro y cuevas-vientre materno; los elementos que parecen más feminoides no habrán dejado de manifestarse antropológicamente con la impronta inversa, etc., etc. Esto que, pese a las dominantes y preferencias comprobadas, debería alertar contra todo apriorismo, ya que finalmente, como en casi todo, el criterio-control es el problemático contexto específico, no deja de predisponer peligrosamente a él. Ya se sabe la preferencia antropológica - atestiguada en multitud de mitos, ritos, textos religiosos, artísticos, sueños, etimologías, etc.- que vincula axiológicamente la ascensión, el vuelo y el cielo a la positividad, espiritualidad y trascendencia, y el descenso y lo subterráneo a la negatividad. Tomado como patrón apriorístico puedo aplicarlo siempre que el hecho «encaje», y no tengo

7 No hay más que leer el gran manual de arquetipología de G. Durand, 1960. La arquetipología nos muestra la asignación «universal» de ciertas valencias simbólicas a determinados objetos, seres, movimientos, etc., pero no que sean las únicas asignables (se comprueba cómo pueden activarse simbólicamente unas $u$ otras de sus diversas cualidades) ni que les corresponda siempre y en todos los casos ese valor simbólico. 
más que guardar silencio ante cualquier contradicción y desconcierto: ¡Qué innegable acierto el de Vicente Aleixandre al ver su «Ciudad del paraíso» (en Sombra del paraíso, 1944), «más alta que el mar», con «flores tropicales [que] elevan sus juveniles palmas gruesas. / Palmas de luz que sobre las cabezas, aladas,...», «momento que en la mente de un Dios emergiste», "ciudad voladora [...], blanca en los aires», «Ciudad que en él [cielo] volabas con tus alas abiertas"! (para lo de "tu vertical caída" valen, en cambio, explicaciones más triviales que la encarnación de impulsos imaginarios). ¿Cómo explicar la plenitud del ex-céntrico, al margen del centro convencional o mayoritario? ¿Es que no le sirve el arquetipo del centro, tan sancionado antropológicamente, 0 simplemente ha erigido otro centro hincando la punta del compás en ese centro de su propio corazón?

Ciertamente la tarea del análisis sémico, de captación, «creación» e interpretación de los contenidos y de los aspectos - textuales y extratextualesque los originan, suele «caer» - salvemos a los críticos más avisados y cautos- en modelos preestablecidos que, tras un tiempo inicial de fascinación y difusión, y una vez aplicados ya a muchos textos, nos acaban pareciendo banales, mecánicos, y llenos de sospechosas reducciones y generalizaciones (igualmente, al acabar encontrando los rasgos «más poderosamente eficaces» en multitud de obras, esos análisis suelen evidenciar que seguimos sin saber revelar verdaderamente las causas que puedan explicar esencialmente el carácter y efecto diferenciados de las grandes frente a las pequeñas obras artísticas). En fin, añadamos unas gotas de aplicación como plantilla de la Poética de lo imaginario a la estrategia estructuralista habitual y riámonos tal vez de nosotros mismos con el cuento antes citado, tal como plantea ahora el análisis T. Eagleton:

Un crítico estructuralista esquematizaría el cuento dentro de una forma diagramática. La primera unidad de significado: «el chico se disgusta con el padre» podría re-escribirse como «rebelión del de abajo contra el de arriban. La caminata del muchacho por el bosque es un movimiento a lo largo de un eje horizontal, lo cual contrasta con el eje vertical «el de abajo/el de arriba», y podría clasificarse como de "posición central». La caída en el hoyo, o sea, debajo del nivel del suelo, de nuevo significa «de abajo», mientras que el cenit solar significa «de arriba». Al lanzar sus rayos al fondo del hoyo, el sol, en cierto sentido, se ha inclinado hacia «abajo» e invertido la primera unidad significativa del relato. La reconciliación entre padre e hijo restablece el equilibrio entre «abajo» y «arriba», y el regreso juntos a casa, que significa «posición central», marca el logro de un estado satisfactoriamente intermedio. Entusiasmado con su triunfo, 
el estructuralista acomoda de nuevo sus esquemas y procede con el siguiente cuento. (1983, pp. 118-119).

El resultado obtenido al ceder la palabra a mi habitual auditorio universitario para realizar un análisis del relato de Montserrat Roig «El canto de la juventud» (1989), es lo que, finalmente, me ha impulsado a plantear las consideraciones anteriores. En este relato una voz narrativa heterodiegética, pero con focalización interna, sometida sin resquicios a las percepciones y valoraciones del personaje central —una anciana que se encuentra hospitalizada-, nos cuenta la última mañana de vida de esta mujer que lucha, asiéndose al recuerdo gratificante, contra la inminencia de la muerte. Su asidero frente a la muerte es el recuerdo, lo que hace que diversas realidades que ve y oye en el hospital le sirvan como trampolín asociativo para transportarse analépticamente al vigoroso episodio de la fascinación en su juventud ante un muchacho forastero con quien tuvo de inmediato su iniciación sexual. El relato está marcado por el juego de las anacronías narrativas, con un continuo vaivén del presente de vejez e inminencia de la muerte - en una habitación en que la anciana asiste a la muerte de otras compañeras tras un biombo- al pasado de juventud y rotundo conocimiento amoroso-sexual. Pero lo que me importa aquí es señalar, brevemente y a título de ejemplo, algunas de las hipersemantizaciones y apriorismos que el ejercicio interpretativo-analítico puso, a mi juicio, de relieve.

Desde el primer párrafo se nos da a conocer que se habla de alguien que está en un hospital tendido en la cama, persona que al despertar al amanecer «miró hacia arriba: por la ventana entraba la luz lechosa de la primera hora del día» (p. 11). Ya comenzaba a haber de dónde sacar materia para el análisis: mirar hacia arriba y luz del mundo exterior = lo positivo frente a un negativo y oprimente espacio interior cerrado. Todos estaban convencidos de la pertinencia de esta oposición, aunque no parezca caber otra cosa que mirar hacia arriba a la ventana cuando se está tumbado, y aunque el co-texto no revelase ninguna valoración explícita positiva del exterior (esto, claro está, no dejaba de formar parte de la estructura profunda, no manifestada; era parte de las presuposiciones postuladas por el propio texto). No había más que realzar la secuencia evidentemente ratificadora en que el rayo de sol que penetra en la habitación trazando una línea de danzantes motas de polvo, y con el que la anciana juega tiernamente interponiendo su mano, le remite a su mano joven ante el sol crepuscular en una naturaleza con vides que «formaban líneas pa- 
ralelas, como el rayo de sol que hacía danzar las motas de polvo" (p. 17). Bastaba con restar relevancia significativa globalizadora a un inoportuno pasaje en que tras señalar que adivinaba «por la ventana un destello de cielo azul», se seguía: «el polvo danza antes de convertirse en ceniza, pensó, al tiempo que giraba la cara hacia el otro lado. No quería ver el rayo de sol" (p. 15). Del mismo modo, no debía de ser tan importante que en el episodio recordado tan positivo fuese el bar (interior) en que conoce al subyugante joven - y los aseos en que por vez primera entran en contacto- como la viña donde poco después consuman sexualmente su atracción (la viña era un estupendo acierto: connotaba lo báquico, orgiástico y sexual). Es éste un hábito que no falta aun en algunos grandes críticos: lo que se ajusta a lo que el intérprete ha decidido dar relevancia tiene un valor generalizante; lo que no, se minimiza y no va más allá de ser un aspecto puntual y transitorio. Quizá no deja de saberse que cuando una isotopía de lectura o una orientación interpretativo-analítica no se ven suficientemente confirmadas por el texto y su contexto, o no conducen a ningún esclarecimiento, hay que renunciar a las expectativas que nos habiamos forjado a partir de los primeros indicios y señales y volver a interpretar con otra orientación, pero solemos resistirnos a los re-planteamientos.

Otro tanto vino a ocurrir con otra anotación del primer párrafo en que la anciana al despertar «vio las paredes blancas, despintadas» de la sala del hospital (p. 11). La blancura, simbólica del candor o la pureza, ya se sabe que también puede serlo en otros contextos del vacío, la ausencia, la desventura (éste era uno de ellos). Esta vez era claro que aquello no podía generalizarse, ya que después es la recurrente bata blanca del médico la que actúa muy positivamente para suscitar la asociación con la recurrente camisa blanca del muchacho que conoció en su juventud en el bar (también aparecen unas recurrentes baldosas blancas en los aseos). Había quien no había percibido —más que inconscientemente en todo caso: gran asidero para justificar la asignación de sentidos por parte de cualquier analista - el contraste entre esa blancura positiva y la negrura de un sacerdote al que la moribunda acoge muy poco favorablemente. Sin embargo, los alumnos avisados y sabedores de que el color da mucho juego sémico en los textos literarios, hasta habían computado las siete veces que aparecía el negro al hablar del cura - generalmente con la fórmula perifrástica metonímica de «el joven vestido de negro»-, lo que hacía que no cupiese duda de la relevancia de esta oposición sémica valorativa encarnada en el color (sancionada porque se había dicho que «el negro es el color de los que olfatean la muerte», p. 14). Claro que de ese juego había que excluir el que en medio de las referencias cromáticas así valoradas se exaltase «el pelo negro, algo rizado» del forastero y del médico (p. 13). Sin duda el análisis cro- 
mático hubiese quedado mucho más ajustado si la autora del texto no hubiese tenido la desafortunada ocurrencia de hablar de las paredes blancas de la habitación de hospital y del pelo negro de aquellos dos jóvenes.

Pero la cima en el uso del apriorismo analítico se alcanzó cuando todos silenciaron el valor significativo de una dualidad que, preguntados por ella, reconocieron que sí habían visto pero que atentaba contra el decisivo arquetipo antropológico de la oposición abajo (descenso) / arriba (ascensión) ${ }^{8}$. ¿Qué insuperable comentario relativo a los valores simbólico-antropológicos asignados a esta oposición espacial de haber sucedido las cosas a la inversa!; pero nada menos que Roig, en su invención ficcional, había cometido la incongruencia de situar arriba del hospital la sala de los moribundos («dos viejas instaladas en la habitación del piso de arriba, trasladadas desde la sala grande para morir allí», p. 12), y no sólo hablar, sino insistir en una prometedora bajada a la sala grande (pp. 14 y 16), donde estaban los enfermos fuera de peligro. ¿Por qué esa resistencia a reconocer que en los límites de una obra o de un sueño el descenso puede tener valores positivos sin atentar contra ningún principio antropológico, o no corresponder a ningún valor sémico más allá del fortuito que tiene por función el mero «efecto de realidad»?

En definitiva, para un analista ortodoxamente heredero de la estilística y del estructuralismo, bañado de poética de la imaginación y compañero de la pragmática semiótica, no sé si todo se semantiza, pero casi todo se puede manejar a conveniencia de unas sistemáticas preestablecidas. Yo creo que si un análisis sólo puede hacerse a partir de modelos, deben ser modelos abiertos que soporten la tensión de confirmaciones y contrariedades, viviendo quizá siempre en ese difícil trance entre sistemática categorial -reduccionista, y hasta organizativamente ideologizada - y contacto con la concreción del objeto y sus circunstancias - concreción generalmente más compleja, y «sistemática» e ideologizada de otro modo-. Si no, los grandes logros acaban apareciendo, paradójicamente, como los grandes fracasos y decepciones - ¿inevitables? - a la hora del análisis del texto literario. Unos acaban creando y acabamos otros aprendiendo y tal vez enseñando lógicas de lectura, interpretación y análisis (la lingüístico-estilística, estructuralista, narratológica,

El resto del relato sí confirmaba las revelaciones de la antropología: los jóvenes se reúnen para consumar su atracción sexual en «los viñedos altos», «el camino hacia los viñedos altos era muy largo. Arriba, en los riscos, una bola de fuego la deslumbraba. Costaba subir allí [pero iba a merecer la pena]» (pp. 16, 17 y 18). 
psicoanalítica, imaginario-simbólica, sociológica...; casi códigos con sus correspondientes tics inevitables), lógicas que terminan perdiendo su valor -como los símbolos racionalmente codificados- convertidas en meras alegorías intelectuales, con vida separada de su carne, de su objeto. En esto seguramente el análisis crítico - y su teoría - deba parecerse al arte: le conviene vivir siempre sintiendo lo concreto, sin racionalizaciones absolutas y en acción de huida del código. 


\section{REFERENCIAS BIBLIOGRÁFICAS}

BARTHES, Roland (1964), Elementos de Semiología, Madrid, Alberto Corazón, 1971 (También en La aventura semiológica, Barcelona, Paidós, 1990, pp. 17-83).

- (1966), «Introducción al análisis estructural de los relatos», en VV. AA., Análisis estructural del relato, Buenos Aires, Tiempo Contemporáneo, 1970, pp. 9-43 (También en La aventura semiológica, Barcelona, Paidós, 1990, pp. 163-201).

- (1968), «El efecto de realidad», en El susurro del lenguaje, Barcelona, Paidós, 1987, pp. 179-187.

Bobes Naves, M." del Carmen (1987), Semiología de la obra dramática, Madrid, Taurus.

- (1989), La Semiología, Madrid, Síntesis.

DOLEŽEL, Lubomir (1986), «Semiotics of Literary Communication», Strumenti critici, I, 1, pp. 5-48.

DURAND, Gilbert (1960), Las estructuras antropológicas de lo imaginario (Introducción a la arquetipologia general), Madrid, Taurus, 1982.

- (1964), La imaginación simbolica, Buenos Aires, Amorrortu, 1971.

EAgleton, Terry (1983), Una introducción a la teoria literaria, México, F.C.E., 1988.

García Berrio, Antonio (1973), Significado actual del formalismo ruso, Barcelona, Planeta. 
GENETTE, Gérard (1969), «Langage poétique, poétique du langage», en Figures II, París, Seuil, pp. 123-153.

LoTMAN, Yuri M. (1970), Estructura del texto artístico, Madrid, Istmo, 1978.

MUKAR̆ovsK\}, Jan (1946), «Sobre el estructuralismo», en Escritos de estética y semiótica del arte, Barcelona, Gustavo Gili, 1977, pp. 157-170.

PARRA, Nicanor (1972), Antipoemas (Antología), Barcelona, Seix Barral.

POSNER, Roland (1976), «Comunicación poética frente a lenguaje literario, o La falacia linguística en la poética», en J. A. Mayoral (ed.), Pragmática de la comunicación literaria, Madrid, Arco/Libros, 1987, pp. 125-136.

RoIG, Montserrat (1989), «El canto de la juventud», en El canto de la juventud, Barcelona, Península, 1990, pp. 9-19.

SONTAG, Susan (1964), «Contra la interpretación», en Contra la interpretación (y otros ensayos), Barcelona, Seix Barral, 1984, 2." ed., pp. 15-27.

TINIANov, Iuri (1924), El problema de la lengua poética, Buenos Aires, Siglo XXI, 1975, 2." ed. 